\title{
Experimental study on granite and the determination of its true strain-rate effect
}

\section{Abstract}

To accurately determine the true strain-rate effect of granite in split Hopkinson pressure bar (SHPB) tests, systematic experimental studies from quasi-static to dynamic loading on the same batch of granite samples is required. Therefore, firstly, splitting, uniaxial and triaxial compression tests were used to study the mechanical response of granite under different static stress conditions with the MTS rock mechanics test system, and the impact compression tests were performed at different strain-rates by the split Hopkinson pressure bar (SHPB). The test results show that the compressive strength increases with the increase of confinement, but the increase rate decreases as the confinement gets larger. The axial failure strain also increases with the increase of confinement. Failure is related to the composition and structure of granite, as well as the stress state. With increasing confinement, the sample is more constrained, the elastic limit strain becomes smaller, and the elastic modulus becomes larger accordingly. In addition, shear slip failure takes place under triaxial compression. In the dynamic compression tests, the strain-rate affects not only the strength of granite, but also the degree of fragmentation and the breaking pattern. Also, it has been found that the dynamic compressive strength enhancement of rocks under impact loading is due to the combined effects of the material strain-rate, lateral inertia and end friction; however, in SHPB tests they are coupled together and could not be separated from each other. To determine the material strain-rate effect of rocks in the SHPB tests, the dynamic compressive strength enhancement caused by the lateral inertial effect and end friction effect needs to be removed. Assuming that the effect of the material strain-rate, lateral inertia and end friction is uncoupled, the numerical simulation method has been employed to simulate the SHPB tests on granite. The true strain-rate effect of granite in SHPB tests is thus determined.

\section{Keywords}

Granite; confinement; strain-rate effect; lateral inertial effect; end friction effect; SHPB test damage tolerance; Weibull distribution.

\author{
Yong Cai ${ }^{\mathrm{a}}$ \\ Shuisheng $\mathrm{Yu}^{\mathrm{b}}$ \\ Yubin Lu ${ }^{c^{*}}$ \\ ${ }^{\mathrm{a}, \mathrm{c}}$ Key Laboratory of Testing Technology \\ for Manufacturing Process (Ministry of \\ Education), Southwest University of \\ Science and Technology, Mianyang \\ 621010, PR China \\ a caiyong@swust.edu.cn \\ ${ }^{\mathrm{b}}$ College of Resources and Civil Engineer- \\ ing, Northeastern University, Shenyang \\ 110819, PR China \\ Corresponding author: \\ *yubinluzju@hotmail.com \\ http://dx.doi.org/10.1590/1679-78251331
}

Received 06.05.2014

In revised form 21.10.2014

Accepted 06.11.2014

Available online 11.11.2014 


\section{INTRODUCTION}

The strength and deformation characteristics of rocks are the foundation of rock engineering design and theoretical analysis. Therefore, systematic experimental studies should be conducted on rocks under complicated geological conditions, for comparative analysis on the test results in different perspectives. Meanwhile, rocks are often inevitably subject to impact loading, which requires study on the dynamic strength of rocks under medium and high strain-rates. The split Hopkinson pressure bar (SHPB) is one of the most often used techniques to determine the dynamic compressive strength of rocks under impact loading. Many SHPB test results on rocks have shown that the dynamic compressive strength increases with the increase of strain-rate (Lu et al., 2010). The same is true of granite. For the experimental study on granite, Zhai et al. (2007) studied the dynamic fracture under uniaxial impact compressive loading, and gave an explanation of the strain-rate dependence of dynamic strength and fragmentation degree. Hong et al. (2008) studied the dimension effect and strain-rate sensitivity of dynamic strength. Ren et al. (2010) performed dynamic compression tests on $\phi 74 \mathrm{~mm}$ SHPB equipment, and used numerical simulations to verify the effectiveness of the dynamic tests. Dai and Xia (2013); Dai et al. (2013) suggested that the fracture toughness of Barre granite shows clear loading rate dependence.

In SHPB tests, the compression strength enhancement caused by the apparent strain-rate effect is often characterized by dynamic increase factor (DIF), which is defined as the ratio of the dynamic strength at a certain strain-rate to the quasi-static strength. However, does the increase of DIF with strain-rate obtained from SHPB tests under high strain-rates only cause by the strain-rate dependence of the measured material itself? Here it should be noted that strain-rate effect induced by the inner structures of the tested material should be considered as the intrinsic strain-rate dependence. Or do structure effects due to the specimen size effect, lateral inertial effect and end friction effect on the contact surface between the specimen and SHPB bars also influence? For this question, researchers have conducted a lot of work. Zhu et al. (2012) considered that the DIF under combined static and dynamic loading is dependent of the rock heterogeneity, static stress and strain-rate. Dai et al. (2010) used lubricated, dry and bonded conditions to examine the end friction effect on rock specimens. Iwamoto and Yokoyama (2012) pointed out that the radial inertia and end friction effects are coupled to each other in SHPB tests. Zhang and Zhao (2013) analyzed the end friction effect and inertia effect. Hao and Hao (2013); Hao et al. (2013) studied the influences of lateral inertia confinement, end friction confinement and aggregates in high-speed impact tests on dynamic compressive properties of concrete. Together with other researchers' studies (Brace and Jones, 1971; Bischoff and Perry, 1991; Li and Meng, 2003; Zhou and Hao, 2008; Liang et al., 2008; Li et al., 2009; Lu et al., 2010; Mu et al., 2012; Hao et al., 2012), it is shown that the lateral inertial effect and the end friction effect are the key factors to cause the increase of DIF in addition to the strain-rate effect of rock material itself (here called the true strain-rate effect), and the three factors are mutually coupled. The lateral confinement caused by the lateral inertial effect and end friction effect leads to the stress state transformation of samples from one-dimensional stress state to multidimensional stress state and even onedimensional strain state, thus raising the dynamic compressive strength of rocks.

In SHPB tests on rocks, if the DIF obtained from SHPB tests is used to directly describe the dynamic compressive strength enhancement, which will overestimate the real dynamic compres- 
sive strength of rocks. However, as an ideal state of SHPB tests cannot be achieved, the lateral inertia effect and end friction effect cannot be eliminated from the test results to obtain the true strain-rate effect. Therefore, a numerical simulation method is required to determine the lateral inertia effect and end friction effect of granite samples, and then the dynamic compressive strength enhancement caused by the lateral inertial effect and end friction effect, respectively, is eliminated from the measured dynamic compressive strength of granite samples. The true strainrate effect of granite in SHPB tests is thus obtained. In this instance, systematic experimental studies from quasi-static to dynamic loading on the same batch of granite samples is needed to obtain reliable true strain-rate effect, however, which are non-existent in existing literature. Otherwise, the material properties of numerical simulation model can only use experimental data from various references, and the determined true strain-rate effect might be unreliable. Therefore, systematic experimental studies on the mechanical properties of granite are conducted in this study. First, splitting, uniaxial and triaxial compression tests are performed in this study to describe the mechanical properties of granite from different perspectives, and provide experimental based parameters for the following numerical simulations. Second, dynamic compression tests are also conducted with $\phi 75 \mathrm{~mm}$ SHPB device.

\section{SPECIMEN PREPARATION AND TEST PROCESS}

To study the mechanical characteristics of granite under different stress conditions, the splitting, uniaxial and triaxial compression tests, as well as the SHPB tests were carried out.

\subsection{Sample preparation}

Granite samples were obtained from the Laizhou mine field in Shandong Province, China, with the appearance of white sesame. The main mineral composition of the granite samples is albite, potassium feldspar, quartz and zeolite. The $\phi 50 \times 100 \mathrm{~mm}$ cylindrical samples were used for uniaxial and triaxial compression tests, and splitting tests used $\phi 50 \times 25 \mathrm{~mm}$ cylinder samples. $\phi 74 \times 37 \mathrm{~mm}$ and $\phi 50 \times 25 \mathrm{~mm}$ cylinder samples were employed for SHPB tests. The average density of granite is $2597 \mathrm{~kg} / \mathrm{m}^{3}$. The granite samples were grinded by a grinding machine, to ensure that the parallelism between the top and bottom surface of samples is within $0.05 \mathrm{~mm}$. The machining precision and basic dimensions of granite samples are in line with the ISRM test standard.

\subsection{Test process}

Splitting, uniaxial and triaxial compression tests were carried out on the MTS-815 Flex Test GT rock mechanics test system as shown in Figure 1. While SHPB tests were carried out on the SHPB device (Figure 2).

\subsubsection{Splitting tests}

The loading method of splitting tests is axial loading with the displacement speed of 0.05 $\mathrm{mm} / \mathrm{min}$, until the samples are failed. The process of splitting test is shown in Figure 3. 


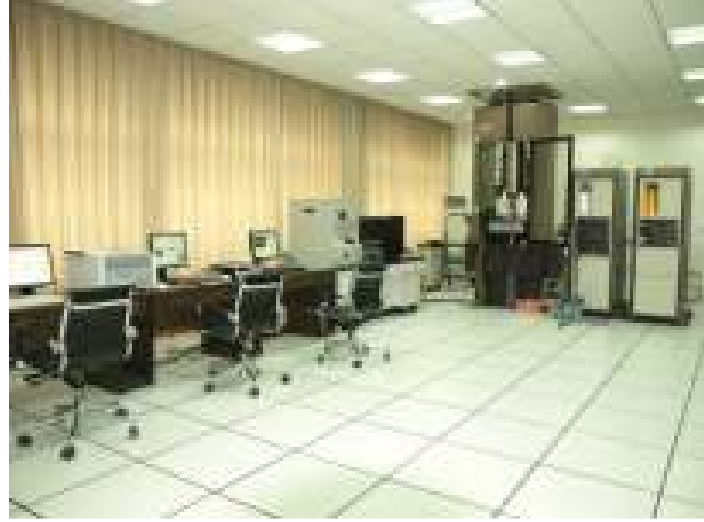

Figure 1: MTS-815 Flex Test GT rock mechanics test system.

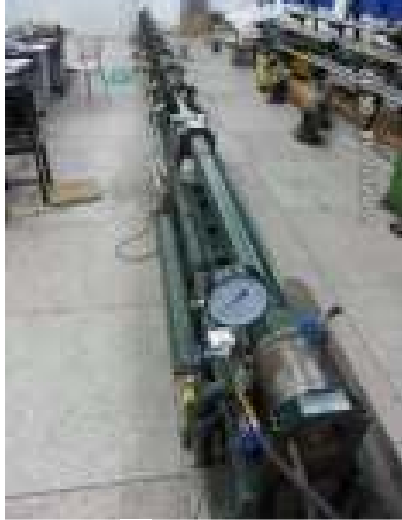

Figure 2: $\phi 75 \mathrm{~mm}$ SHPB device.

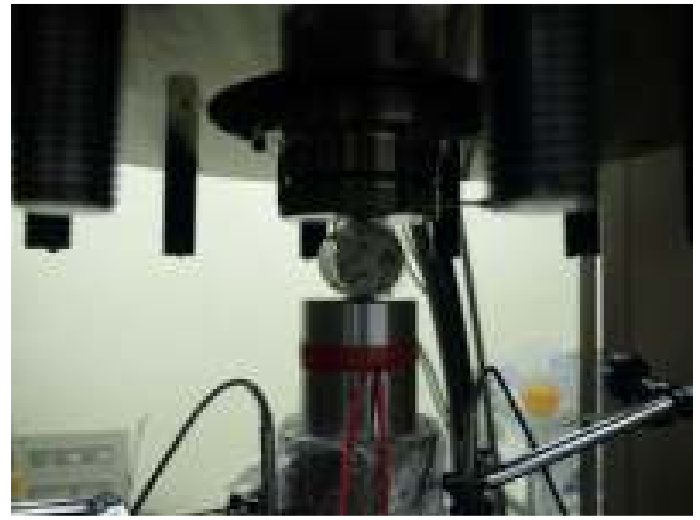

Figure 3: The process of splitting test.

\subsubsection{Uniaxial compression tests}

The loading method is using the axial load control mode to load the samples to $100 \mathrm{kN}$ with the loading speed of $60 \mathrm{kN} / \mathrm{min}$, and then the lateral deformation control mode to load the samples with the displacement speed of $0.02 \mathrm{~mm} / \mathrm{min}$. To reduce the end friction effect to the test results, the lubricant of Vaseline was smeared on both ends of specimens before tests. The process of uniaxial compression test is shown in Figure 4.

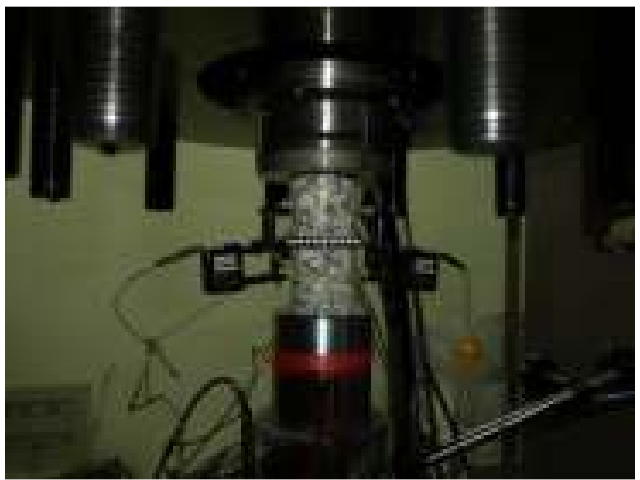

Figure 4: The process of uniaxial compression test. 


\subsubsection{Triaxial compression tests}

The confinement pressure was applied to the predetermined values with the rate of $6 \mathrm{MPa} / \mathrm{min}$. At this stage, the samples were under hydrostatic pressure state. Then the samples are loaded initially in the axial direction to $100 \mathrm{kN}$ with the rate of $60 \mathrm{kN} / \mathrm{min}$. Finally, the lateral load control mode with the displacement speed of $0.02 \mathrm{~mm} / \mathrm{min}$ is employed until samples lose load bearing capacity and fail. The process of triaxial compression test is shown in Figure 5.

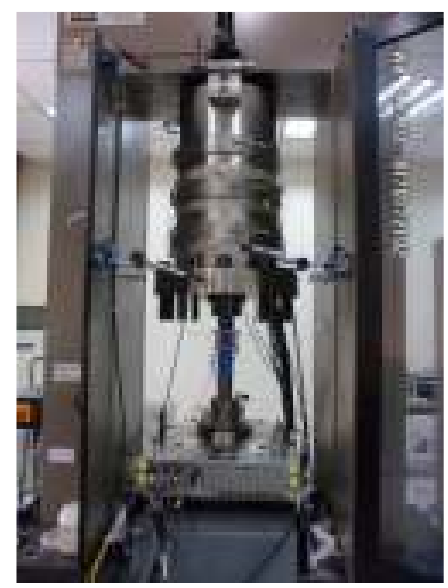

Figure 5: The process of triaxial compression test.

\subsubsection{SHPB tests}

The process of SHPB test is shown in Figure 6. The material of all the bars in SHPB tests is high strength martensitic steel. The common diameter is $75 \mathrm{~mm}$. The length of striker bar, incident bar and transmission bar is $400 \mathrm{~mm}, 6000 \mathrm{~mm}$ and $3500 \mathrm{~mm}$, respectively. To reduce the end friction effect, Vaseline was smeared on the interfaces between specimen ends and incident bar or transmission bar. To ensure that uniform stress state in the loading direction can be achieved as early as possible in granite samples, the amplitude of pulse oscillation can be reduced, and correct pulse shape is obtained for approximate constant strain-rate loading, soft rubber (bicycle inner tube) with the diameter of $35 \mathrm{~mm}$ and the thickness of $1 \mathrm{~mm}$ is employed as pulse shapers through multiple trial tests. The pulse shaper is shown in Figure 7.

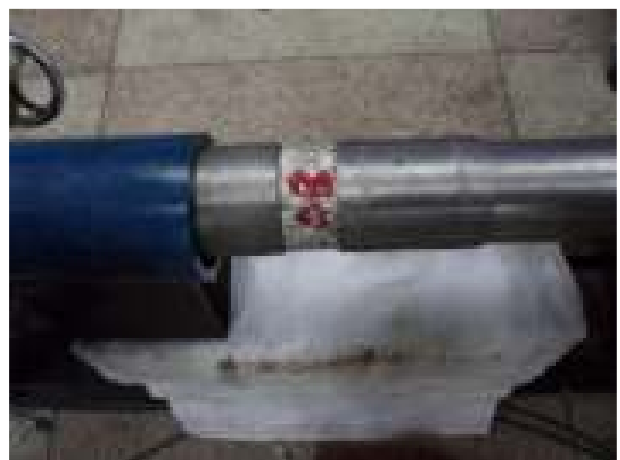

Figure 6: The process of SHPB test.

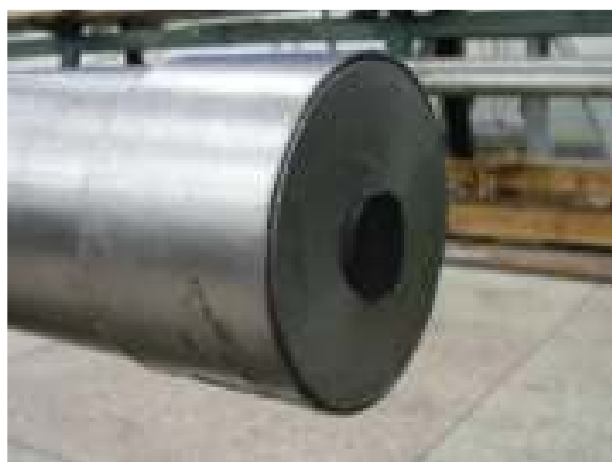

Figure 7: Pulse shaper.

Latin American Journal of Solids and Structures 12 (2015) 675-694 


\section{THE TEST RESULTS AND DISCUSSION}

\subsection{Splitting test results and analysis}

In splitting tests, specimens are basically split into two halves along the middle line. Stress-time curves are shown in Figure 8 and the failure mode of splitting test is shown in Figure 9. The peak stress of the three samples is $6.06 \mathrm{MPa}, 6.43 \mathrm{MPa}$ and $6.88 \mathrm{MPa}$, respectively. Thus the average peak stress is $6.46 \mathrm{MPa}$. Figure 8 showed that when the peak stress is achieved, the specimen is divided into two halves, and then with the increase of time, the stress drops to 0.

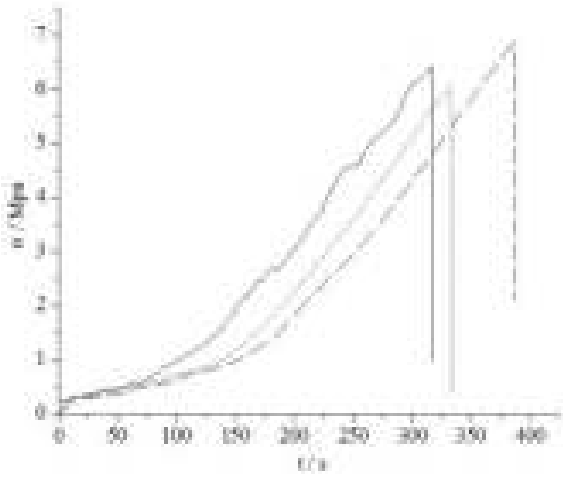

Figure 8: The stress-time curves of splitting tests.

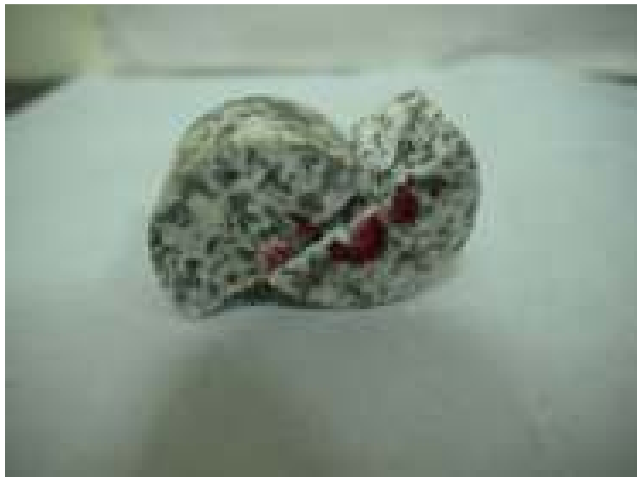

Figure 9: The failure mode of splitting test.

\subsection{Uniaxial compression test results and analysis}
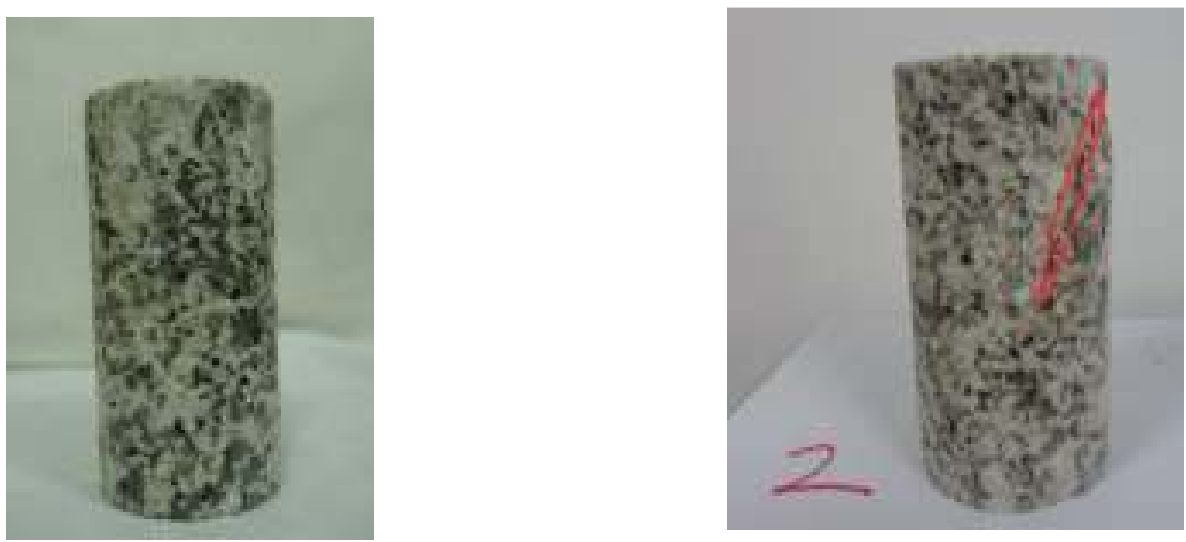

Figure 10: The granite specimen before and after a uniaxial compression test.

The specimen before and after a uniaxial compression test are shown in Figure 10. Splitting cracks with $45^{\circ}$ after tests are appeared on granite samples. The stress-strain curves under uniaxial compression are shown in Figure 11. The compressive strength of the three specimens is 149.79 $\mathrm{MPa}, 142.35 \mathrm{MPa}$ and 147.64 $\mathrm{MPa}$, respectively. The difference among the three results is not large, namely that the discreteness is small. Thus the experimental results are reliable. The average compressive strength of the three specimens is 146.59 MPa. 


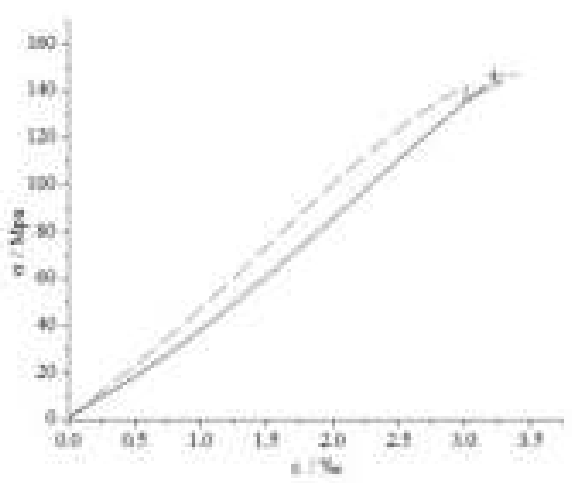

Figure 11: The stress-strain curves of uniaxial compression tests.

The test results are summarized in Table 1, where $\sigma_{s}$ is the uniaxial compressive strength, $\bar{\sigma}_{s}$ is the average of $\sigma_{s}, E_{50}$ and $\nu_{50}$ is the elastic modulus and Poisson ratio when stress is $50 \%$ of the compressive strength, respectively, and $\bar{E}_{50}$ and $\bar{\nu}_{50}$ refers to the average of $E_{50}$ and $\nu_{50}$, respectively. $\bar{\sigma}_{s}, \bar{E}_{50}$ and $\bar{\nu}_{50}$ are obtained based on experimental data, which provide parameters for the following numerical simulations.

\begin{tabular}{ccccccc}
\hline \hline \multirow{2}{*}{ Number } & $\sigma_{s}(\mathrm{MPa})$ & $\bar{\sigma}_{s}(\mathrm{MPa})$ & $E_{50}(\mathrm{GPa})$ & $\bar{E}_{50}(\mathrm{GPa})$ & $\nu_{50}$ & $\bar{\nu}_{50}$ \\
\hline 1 & 149.79 & \multirow{5}{*}{146.59} & 41.70 & & 0.13 & \multirow{2}{*}{0.13} \\
2 & 142.35 & 48.95 & 44.37 & 0.13 & \\
3 & 147.64 & & 42.45 & & 0.13 & \\
\hline \hline
\end{tabular}

Table 1: Results of uniaxial compression tests.

\subsection{Triaxial compression test results and analysis}

The triaxial compression tests were carried out under different confinement pressures of 5, 10, 30, 50, 60 and $80 \mathrm{MPa}$. The failure pattern is shown in Figure 12, where the angle between the maximum principal plane and failure face is about $45^{\circ}$. The failure mode is mainly shear sliding failure, at the same time the characteristic of brittle failure is also obvious.

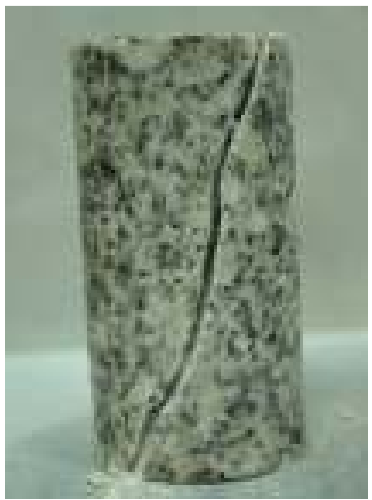

Figure 12: Failure pattern of granite samples under triaxial compression tests. 


\subsubsection{The principal stress-axial strain curves}

The typical principal stress-axial strain curves under different confinement pressures are shown in Figure 13. It is observed that the compressive strength increases obviously with the increase of confinement pressure. Under the confinement pressure, the deformation law of linear elastic stage is approximately same before granite samples yield. However, the straight line under high confinement pressure is slightly higher than that under low confinement pressure. At the same time, with the increase of confinement pressure, the plastic characteristics of granite samples are gradually obvious, because confinement pressure can limit the nucleation and extension of cracks, and prevent the relative sliding between granite grains.

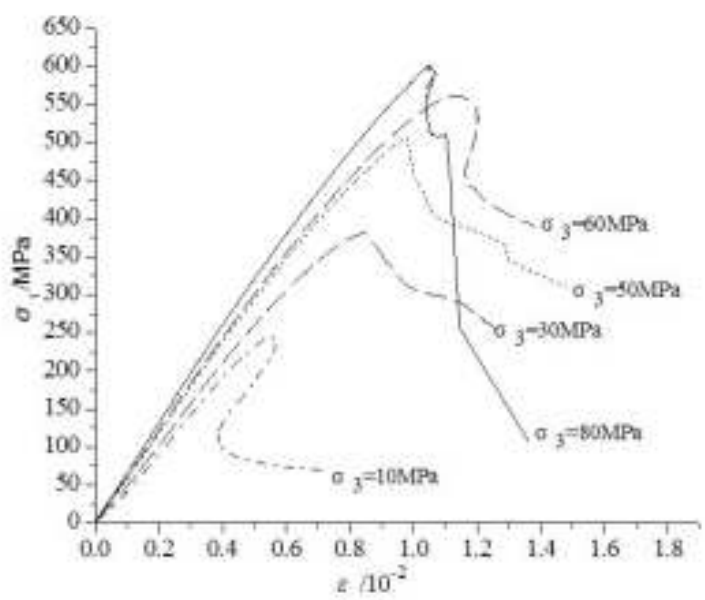

Figure 13: The principal stress-axial strain curves of triaxial compression tests with different confinement pressures.

\subsubsection{The relationship between compressive strength and confinement pressure}

The relationship between compressive strength and confinement pressure is shown in Figure 14. It is found that the compressive strength increases with increasing the confinement pressure. But the increase range of the compressive strength with the increase of confinement pressure tends to decrease, which decreases gradually from $57 \%$ to $9.4 \%$. As under low confinement pressure, the pressure difference is large, microcracks are extremely rich inner specimens, when the principal stress reaches a certain extent, microcracks gradually propagate, which finally lead to specimen failure. With the increase of confinement pressure, the brittle fracture of granite specimens gradually turns to ductile fracture, and the compressive strength increases, but the increase range decreases.

The expression between the average compressive strength $\sigma_{1}$ and the confinement pressure $\sigma_{3}$ is as follows,

$$
\sigma_{1}=-0.04495 \sigma_{3}^{2}+9.09916 \sigma_{3}+164.6
$$

As shown in Figure 14, the fitted curve agrees with the experimental data. 


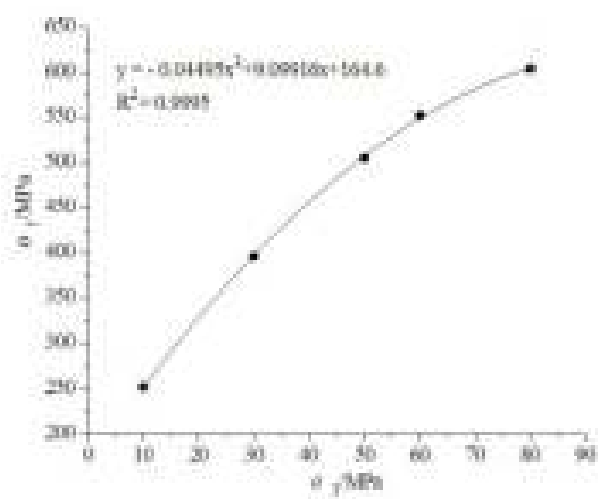

Figure 14: The relation between the average compressive strength and the confinement pressure.

\subsubsection{The relationship between axial failure strain and confinement pressure}

As shown in Figure 15, the axial failure strain increases with increasing the confinement pressure. It explains that the deformation mode of granite samples transforms from brittle under low confinement pressure to plastic under high confinement pressure. It also shows that the deformation failure of granite samples relates not only to their composition and structure, but also the stress state.

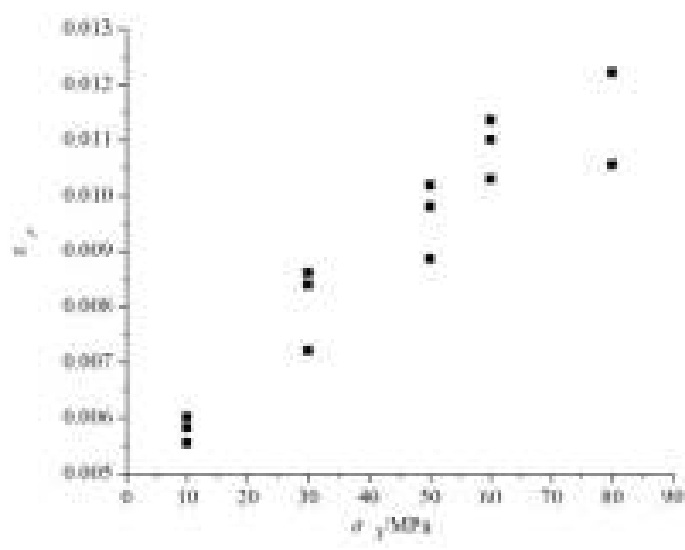

Figure 15: The relation of the axial failure strain and the confinement pressure.

\subsubsection{The relationship between elastic modulus and confinement pressure}

As can be seen from Figure 16, the relationship between the elastic modulus and the confinement pressure is non-linear. With the increase of confinement pressure, the bondage of samples becomes closer, the value of elastic strain becomes smaller, and thus the elastic modulus becomes lager accordingly. The expression between the average elastic modulus $E_{s}$ and the confinement pressure is as follows,

$$
E_{s}=-0.00289 \sigma_{3}^{2}+0.50779 \sigma_{3}+41.6024
$$




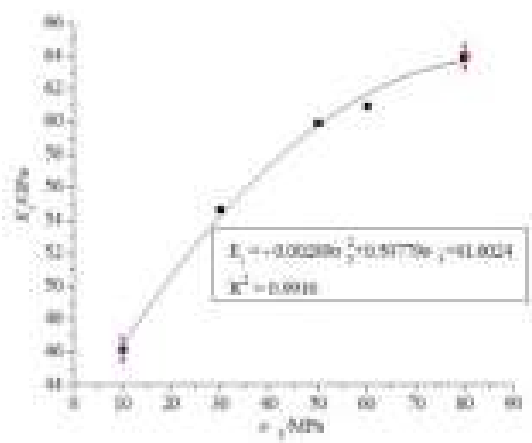

Figure 16: The relation between the average elastic modulus and the confinement pressure.

\subsection{SHPB test results and discussion}

In SHPB tests, the striking velocity is controlled by changing the air pressure, so the amplitude of strain-rate is changed. SHPB tests on granite samples of $\phi 50 \mathrm{~mm}$ and $\phi 74 \mathrm{~mm}$ have been carried out under 3 to 4 kinds of velocities. The test results are summarized in Table 2, where A1-9 are the samples of $\phi 50 \mathrm{~mm}, \mathrm{~B} 1-11$ are the samples of $\phi 74 \mathrm{~mm}$, and C1-8 are the samples obtained from $\phi 74 \mathrm{~mm}$ samples with second processing on $\phi 100 \mathrm{~mm}$ samples. The deviation of strain-rate and peak stress from the corresponding average value is also listed in Table 2 . It is found that most deviation values are within 10\%, thus the degree of data dispersion is small and test results are acceptable.

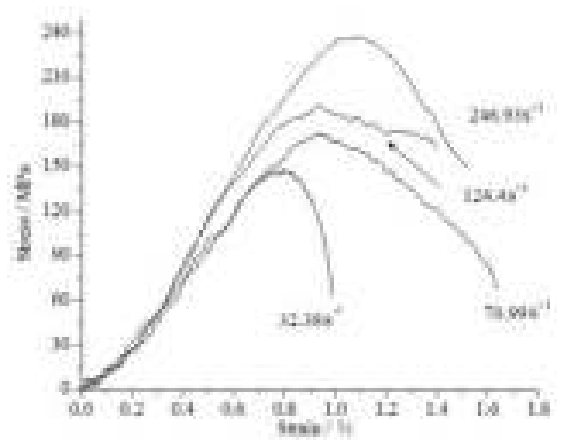

Figure 17: The stress-strain curves under different strain-rates from SHPB tests.

Stress-strain results of $\phi 74 \mathrm{~mm}$ granite samples under different strain-rates are shown in Figure 17. It is found that they have a relation of linear elastic in the early compressive stage. When the stress is increased to a certain level, the rise segment of stress-strain curves gradually deviates from linear elasticity to nonlinearity, which is due to the nucleation and propagation of specimen internal microcracks. After the stress reaches the peak, the material strength does not loss immediately, but gradually weakens with the continuous development of deformation, which is a long decline segment in stress-strain curves. The stress decreases gradually with the development of strain until specimen fails. It is associated with the unstable extension of specimen internal microcracks, and the generation and unstable extension of microcracks lead to the decrease of material strength. The accumulation of material damage leads to the strain softening phenome- 
non. The dynamic compressive strength increases with increasing strain-rate. Thus, the dynamic compressive strength of granite has obvious strain-rate effect.

\begin{tabular}{|c|c|c|c|c|c|c|}
\hline Number & $\begin{array}{l}\text { Air pressure } \\
(\mathrm{MPa})\end{array}$ & $\begin{array}{c}V \\
(\mathrm{~m} / \mathrm{s})\end{array}$ & $\begin{array}{c}\dot{\varepsilon} \\
\left(\mathrm{s}^{-1}\right)\end{array}$ & $\begin{array}{c}\overline{\dot{\varepsilon}} \\
\left(\mathrm{s}^{-1}\right)\end{array}$ & $\begin{array}{c}\sigma_{p} \\
(\mathrm{MPa})\end{array}$ & $\begin{array}{c}\bar{\sigma}_{p} \\
(\mathrm{MPa})\end{array}$ \\
\hline A-1 & \multirow{3}{*}{0.40} & \multirow{3}{*}{10.25} & $175.85(-2.0 \%)$ & \multirow{3}{*}{179.46} & $238.63(9.3 \%)$ & \multirow{3}{*}{218.30} \\
\hline A-2 & & & $177.56(-1.1 \%)$ & & $202.60(-7.2 \%)$ & \\
\hline A-3 & & & $184.98(3.1 \%)$ & & $213.68(-2.1 \%)$ & \\
\hline A-4 & \multirow{3}{*}{0.50} & \multirow{3}{*}{13.54} & $288.70(13.5 \%)$ & \multirow{3}{*}{254.36} & $247.76(1.3 \%)$ & \multirow{3}{*}{244.67} \\
\hline$A-5$ & & & $233.48(-8.2 \%)$ & & $252.77(3.3 \%)$ & \\
\hline A- 6 & & & $240.90(-5.3 \%)$ & & $233.48(-4.6 \%)$ & \\
\hline A-7 & \multirow{3}{*}{0.60} & \multirow{3}{*}{16.87} & $298.37(4.3 \%)$ & \multirow{3}{*}{286.19} & $276.55(4.5 \%)$ & \multirow{3}{*}{264.55} \\
\hline A-8 & & & $254.22(-11.2 \%)$ & & $236.37(-10.6 \%)$ & \\
\hline A-9 & & & $305.98(6.9 \%)$ & & $280.72(6.1 \%)$ & \\
\hline B-1 & \multirow{2}{*}{0.40} & \multirow{2}{*}{10.25} & $32.38(9.2 \%)$ & \multirow{2}{*}{29.64} & $150.34(-6.6 \%)$ & \multirow{2}{*}{160.98} \\
\hline B-2 & & & $26.90(-9.2 \%)$ & & $171.62(6.6 \%)$ & \\
\hline B-3 & \multirow{3}{*}{0.45} & \multirow{3}{*}{12.72} & $70.99(-15.5 \%)$ & \multirow{3}{*}{84.05} & $174.84(-1.1 \%)$ & \multirow{3}{*}{176.81} \\
\hline B-4 & & & $97.05(15.4 \%)$ & & $198.06(12.0 \%)$ & \\
\hline B-5 & & & $84.12(0.1 \%)$ & & $157.52(-10.9 \%)$ & \\
\hline B-6 & \multirow{3}{*}{0.50} & \multirow{3}{*}{13.54} & $113.44(-6.6 \%)$ & \multirow{3}{*}{121.51} & $186.59(-1.3 \%)$ & \multirow{3}{*}{189.10} \\
\hline B-7 & & & $124.4(2.4 \%)$ & & $189.85(0.4 \%)$ & \\
\hline B-8 & & & $126.69(4.3 \%)$ & & $190.86(0.9 \%)$ & \\
\hline B-9 & \multirow{3}{*}{0.70} & \multirow{3}{*}{17.03} & $246.93(14.0 \%)$ & \multirow{3}{*}{216.64} & $242.20(-0.1 \%)$ & \multirow{3}{*}{242.44} \\
\hline B-10 & & & $162.40(-25.0 \%)$ & & $234.80(-3.1 \%)$ & \\
\hline B-11 & & & $240.60(11.1 \%)$ & & $250.31(3.2 \%)$ & \\
\hline $\mathrm{C}-1$ & \multirow{2}{*}{0.45} & \multirow{2}{*}{12.72} & $48.85(-22.0 \%)$ & \multirow{2}{*}{62.64} & $153.90(-5.4 \%)$ & \\
\hline $\mathrm{C}-2$ & & & $76.43(22.0 \%)$ & & & 162.75 \\
\hline $\mathrm{C}-3$ & & & $123.05(-10.1 \%)$ & & $162.24(-7.8 \%)$ & \\
\hline C-4 & 0.50 & 13.54 & $106.12(-22.5 \%)$ & 136.92 & $217.05(23.4 \%)$ & 175.91 \\
\hline $\mathrm{C}-5$ & & & $181.59(32.6 \%)$ & & $148.44(-15.6 \%)$ & \\
\hline C-6 & & & $129.83(-5.5 \%)$ & & $231.44(11.6 \%)$ & \\
\hline C-7 & 0.70 & 17.03 & $162.42(18.2 \%)$ & 137.39 & $187.55(-9.6 \%)$ & 207.40 \\
\hline C-8 & & & $119.92(-12.7 \%)$ & & $203.21(-2.0 \%)$ & \\
\hline
\end{tabular}

Table 2: The SHPB test results of granite.

Figure 18 is the damage photos of $\phi 74 \mathrm{~mm}$ granite samples under 4 different strain-rates. It shows that with increasing strain-rate, the damage pattern is failure with blocks, broken with the core left, crushing to coarse particles and completely shattered to powder, respectively, which indicates the rate sensitive characteristics of granite on the failure mode, another manifestation of strain-rate effect. In terms of energy, the energy of samples from SHPB system is released by the 
generation and development of material internal microcracks. Thus, the number of microcracks formed and developed is related to the impact loading. Under high strain-rates, a large number of microcracks generate which directly leads to the crushing destruction of samples. But the number of microcracks is relatively less under low strain-rates, thus the damaged particles are bigger.

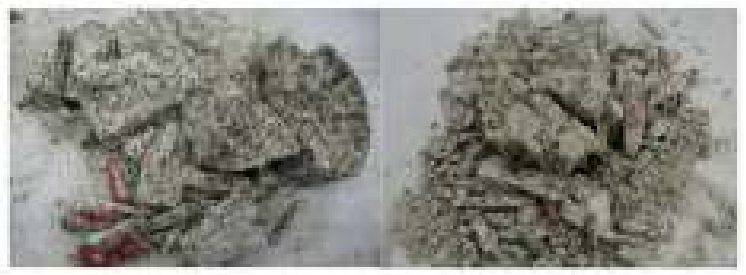

$296.4 s^{-1}$

$8405 \mathrm{~s}^{-1}$

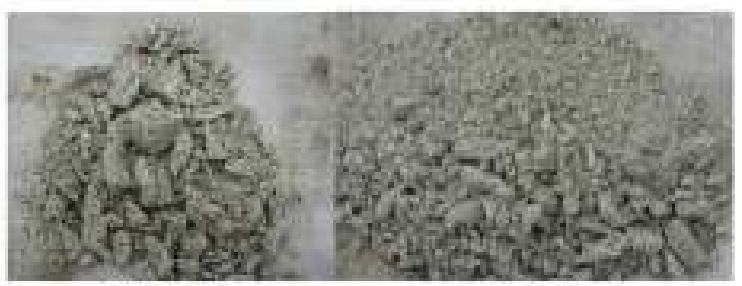

$121.518^{-3}$

$236.64 \mathrm{~s}^{-1}$

Figure 18: Fracture photos of granite specimens under different strain-rates from SHPB tests

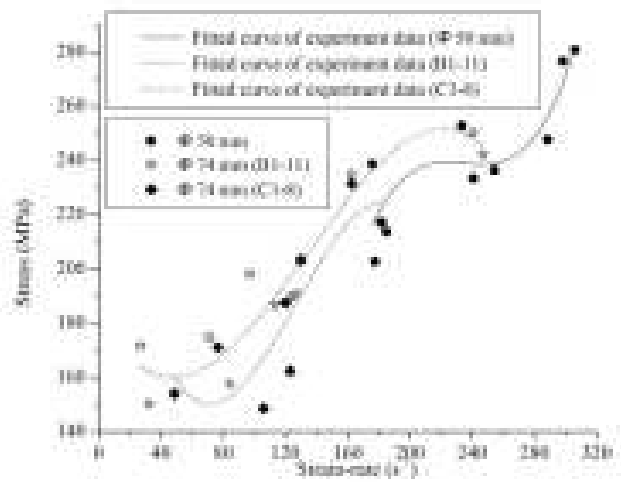

Figure 19: Relationship between the compressive strength and strain-rate for granite samples of different diameters.

Figure 19 shows that the peak strength of granite samples increases with increasing strain-rate, which has strong strain-rate dependence. It can be seen from the fitted curves that for the same diameter of samples, because microcracks may be induced on granite samples by second processing and the micro fracture phenomenon may appear, the peak strength of C1-8 samples is lower than that of B1-11 samples under the same strain-rate.

\section{DETERMINING THE TRUE STRAIN-RATE EFFECT OF GRANITE}

To determine the real strain-rate effect of granite in SHPB tests, the numerical simulation method is used to study the real strain-rate effect and structural response. The extended linear 
Drucker-Prager model (hereinafter referred as D-P model) in ABAQUS (Hibbitt, Karlson \& Sorensen, Inc, 2007) is employed in this study, because the model has been widely used to simulate the dynamic compressive response of rock-like materials in SHPB tests. Thus, determining the parameters of D-P model, i.e., the slope of the linear yield surface in the plane of pseudo effective stress $t$-hydrostatic pressure $p$ (which is called the friction angle, as shown in Figure 20), the dilation angle in the $t-p$ plane (see Figure 20) and the ratio of triaxial tensile and compressive strength (which controlling the influence of the third invariant to the yield surface), are critical.

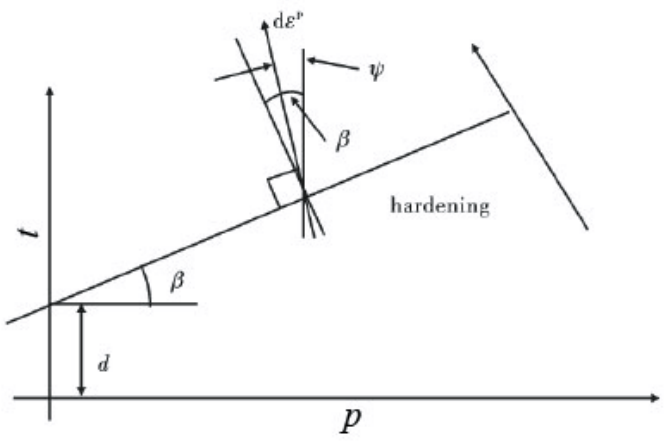

Figure 20: Yield surface and flow direction in the $t-p$ plane of the D-P model.

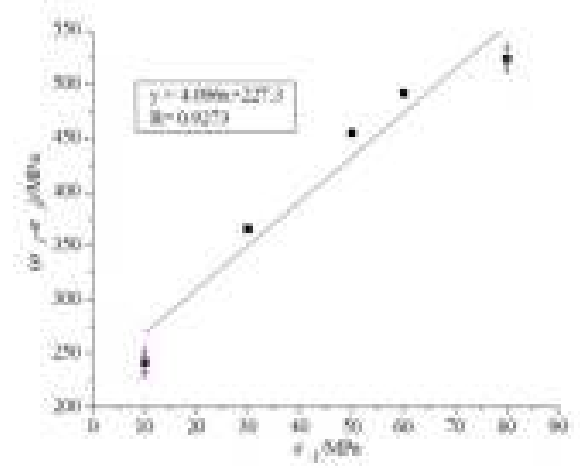

Figure 21: The friction angle of the D-P model based on the triaxial compression tests.

In triaxial compression tests, the relationship between $\left(\sigma_{1}-\sigma_{3}\right)$ and the confinement pressure $\sigma_{3}$ is shown in Figure 21. The slope of the line is the friction angle of the D-P model. The friction angle $\beta$ is obtained by the following Eq.(3), which is $76.3^{\circ}$. And based on the results of uniaxial compression and splitting tests, the dilation angle $\psi$ of granite is obtained by the following Eq.(4), which is $66.3^{\circ}$.

$$
\begin{gathered}
\beta=\arctan 4.096=76.3^{\circ} \\
\psi=\sin ^{-1}\left(\frac{\sigma_{c s}-\sigma_{t s}}{\sigma_{c s}+\sigma_{t s}}\right)=\sin ^{-1}\left(\frac{146.59-6.46}{146.59+6.46}\right)=66.3^{\circ}
\end{gathered}
$$

The material properties of SHPB bars and granite samples are summarized in Table 3 . The parameters $(\beta, \psi, K)$ of granite in the D-P model are also summarized in Table 3 . Since the 
value of the parameter $K$ has negligible influence on the simulation results of DIF, considering the stability of the numerical simulations, the value of $K$ is taken as 1 .

\begin{tabular}{cccccccc}
\hline \hline \multirow{2}{*}{ Material } & $\rho\left(\mathrm{kg} / \mathrm{m}^{3}\right)$ & $\sigma_{s}(\mathrm{MPa})$ & $E(\mathrm{GPa})$ & $v$ & \multicolumn{2}{c}{ D-P model parameters } \\
\cline { 6 - 8 } & & & 210 & 0.30 & & & \\
\hline Steel & 7800 & & & & & & \\
Granite & 2597 & 146.59 & 44.37 & 0.13 & 76.3 & 66.3 & 1 \\
\hline \hline
\end{tabular}

Table 3: Material properties of SHPB pressure bars and granite samples and the D-P model parameters of samples.

In the method of $\mathrm{Yu}$ et al. (2013), it is assumed that the material true strain-rate effect, lateral inertia effect and end friction effect are not related. The results from Yu et al. (2013) are comparable with those from $\mathrm{Lu} \& \mathrm{Li}$ (2011), and the deviations between them are found to be small. Thus, the method of $\mathrm{Yu}$ et al. (2013) is feasible for engineering calculations. So the method of $\mathrm{Yu}$ et al. (2013) is used to determine the true strain-rate effect of granite in this study. The specific steps are as follows.

The DIF obtained from experiments can be expressed as follows,

$$
D I F_{\text {tot }}=\sigma_{\mathrm{d}} / \sigma_{\mathrm{s}}=\left(\Delta \sigma_{\mathrm{d}}+\sigma_{\mathrm{s}}\right) / \sigma_{\mathrm{s}}
$$

Material true strain-rate effect, lateral inertial effect and end friction effect are dependent of the strain-rate. Assuming that they are not related, $\Delta \sigma_{\mathrm{d}}$ can be expressed as follows,

$$
\Delta \sigma_{\mathrm{d}}=\Delta \sigma_{\dot{\varepsilon}}+\Delta \sigma_{i}+\Delta \sigma_{\mu}
$$

Substituting Eq.(6) into Eq.(5), DIF tot can be expressed as follows,

$$
D I F_{\text {tot }}=\left(\Delta \sigma_{\dot{\varepsilon}}+\Delta \sigma_{i}+\Delta \sigma_{\mu}+\sigma_{\mathrm{s}}\right) / \sigma_{\mathrm{s}}
$$

When the true strain-rate effect and end friction effect are not considered, namely $\Delta \sigma_{\dot{\varepsilon}}$ is 0 and friction coefficient is 0 , the DIF increment will be caused only by the lateral inertial effect, therefore

$$
\Delta D I F_{\mathrm{i}}=\sigma_{\mathrm{d}} / \sigma_{\mathrm{s}}-1=\left(\Delta \sigma_{i}+\sigma_{\mathrm{s}}\right) / \sigma_{\mathrm{s}}-1
$$

At the same time, when $\Delta \sigma_{\dot{\varepsilon}}$ is 0 and the lateral inertial effect is not considered, the DIF increment is caused only by the end friction effect, therefore

$$
\Delta D I F_{\mu}=\sigma_{\mathrm{d}} / \sigma_{\mathrm{s}}-1=\left(\Delta \sigma_{\mu}+\sigma_{\mathrm{s}}\right) / \sigma_{\mathrm{s}}-1
$$

Thus, the DIF increment caused only by the true strain-rate effect can be expressed as follows,

$$
D I F_{\dot{\varepsilon}}=\left(\sigma_{\mathrm{d}}-\Delta \sigma_{i}-\Delta \sigma_{\mu}\right) / \sigma_{\mathrm{s}}=\left(\Delta \sigma_{\dot{\varepsilon}}+\sigma_{\mathrm{s}}\right) / \sigma_{\mathrm{s}}=D I F_{\text {tot }}-\Delta D I F_{i}-\Delta D I F_{\mu}
$$




\subsection{The influence of the lateral inertial effect on DIF in SHPB tests}

When studying the influence of lateral inertial effect on DIF in numerical simulations, the DIF values are set to 1 under various strain-rates in the D-P model, the friction coefficient between granite samples and pressure bars is set to 0 , so the true strain-rate effect and the end friction effect of granite samples are not considered. The DIF increment only caused by the influence of lateral inertial effect is the DIF obtained from numerical dynamic compression simulations minus the DIF obtained from quasi-static compression tests. In this study, the lateral inertial effect of $\phi 50$ and $\phi 74 \mathrm{~mm}$ (B1-11) granite samples is determined. The determination of the end friction effect and real strain-rate effect uses the same granite samples. The numerical calculations are performed using the ABAQUS/Explicit version 6.11-1 with element type CAX4R (axi-symmetric element, reduced integration). The numerical models are shown in Figure 22. Contours of radial stress in the numerical SHPB test are shown in Figure 23 and numerical simulation results are shown in Figure 24. Eq.(11) is used to fit the simulation data, where the determination coefficient is 0.944 and 0.997 , respectively,

$$
\left\{\begin{array}{l}
\phi 50 \mathrm{~mm}: D I F_{i}=3.866[\lg (\dot{\varepsilon})]^{3}-25.665[\lg (\dot{\varepsilon})]^{2}+56.702 \lg (\dot{\varepsilon})+40.672 \\
\phi 74 \mathrm{~mm}: D I F_{i}=0.225[\lg (\dot{\varepsilon})]^{3}-0.962[\lg (\dot{\varepsilon})]^{2}+1.392 \lg (\dot{\varepsilon})+0.324
\end{array}\right.
$$

$\Delta D I F_{i}$ is obtained by Eq.(11) minus 1.

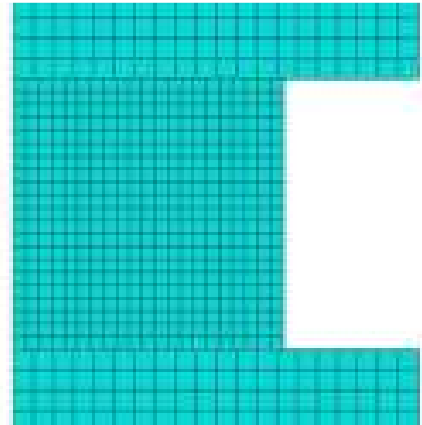

(a) $\phi 50 \mathrm{~mm}$

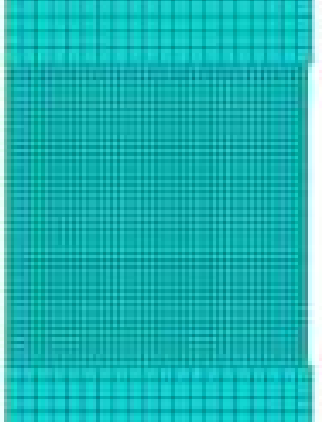

(b) $\phi 74 \mathrm{~mm}$

Figure 22: The numerical model.

\subsection{The influence of end friction effect on DIF in SHPB tests}

In numerical simulations, DIF is set to 1 under different strain-rates in the D-P model, the parameters $(\beta$ and $\psi$ ) related to the lateral inertial effect are set to 0 in the D-P model, and $K$ is still set to 1 , so the true strain-rate effect and the lateral inertial effect of granite samples are not considered. The DIF increment only caused by the influence of end friction effect is the DIF obtained from numerical dynamic compression simulations minus the DIF obtained from quasistatic compression tests. As there are no friction test results available, the friction coefficient is taken as 0.13. Contours of radial stress in the numerical SHPB test are shown in Figure 25 and numerical simulation results are shown in Figure 26. Eq.(12) is used to fit the simulation data, where the determination coefficient is 0.99 and 0.959 , respectively, 


$$
\left\{\begin{array}{l}
\phi 50 \mathrm{~mm}: D I F_{\mu}=2.057[\lg (\dot{\varepsilon})]^{3}-13.851[\lg (\dot{\varepsilon})]^{2}+31.297 \lg (\dot{\varepsilon})-22.65 \\
\phi 74 \mathrm{~mm}: D I F_{\mu}=0.142[\lg (\dot{\varepsilon})]^{3}-0.66[\lg (\dot{\varepsilon})]^{2}+1.025 \lg (\dot{\varepsilon})+0.472
\end{array}\right.
$$

$\Delta D I F_{\mu}$ is attained by Eq.(12) minus 1.

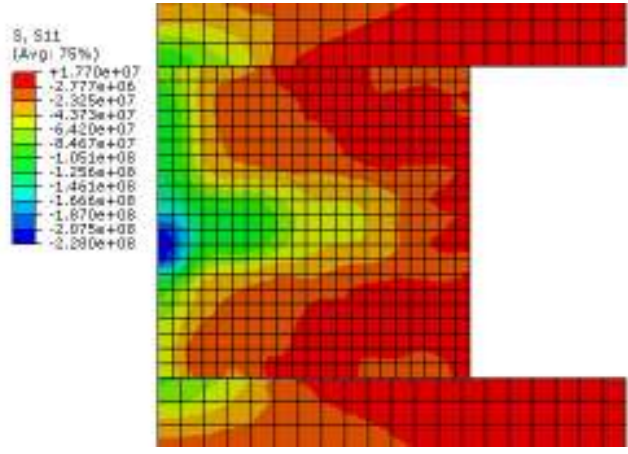

(a) $\phi 50 \mathrm{~mm}$

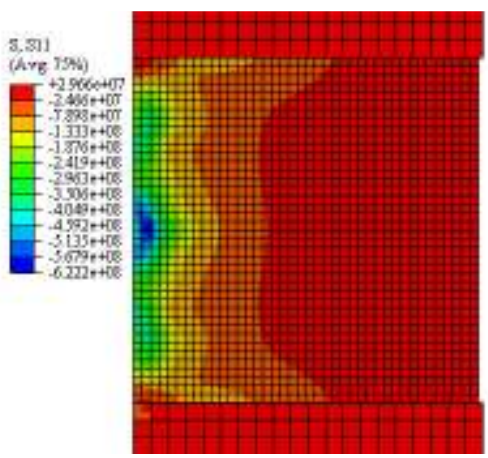

(b) $\phi 74 \mathrm{~mm}$

Figure 23: Contours of radial stress in the numerical SHPB test only considering lateral inertial effect.

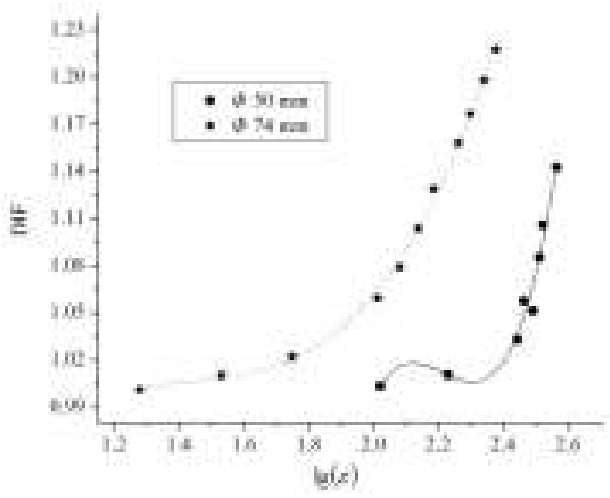

Figure 24: The relationship between DIF and the common logarithmic of strain-rate induced only by the lateral inertial effect.

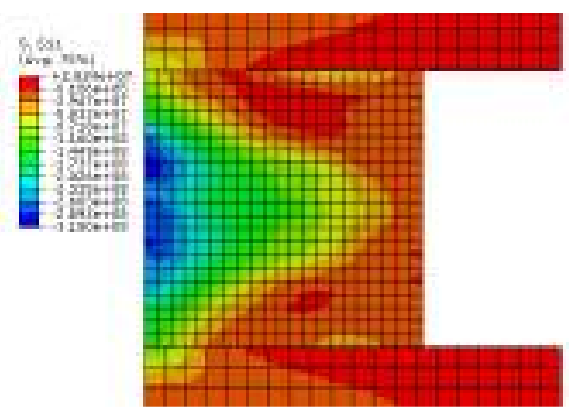

(a) $\phi 50 \mathrm{~mm}$

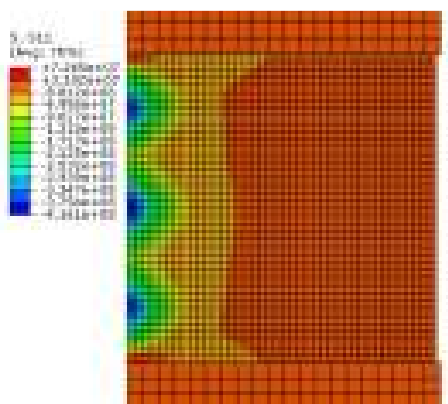

(b) $\phi 74 \mathrm{~mm}$

Figure 25: Contours of radial stress in the SHPB test only considering end friction effect. 


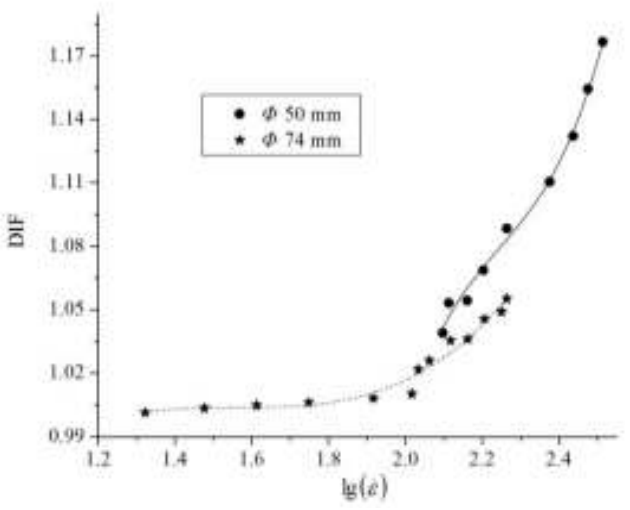

Figure 26: The relationship between DIF and the common logarithmic of strain-rate induced only by the end friction effect.

\subsection{Determining the true strain-rate effect}

DIF results obtained from SHPB experiments are caused by the lateral inertial effect, end friction effect and true strain-rate effect. Thus, when DIF results from SHPB experiments minus the DIF increment caused only by the lateral inertia effect and end friction effect, $D I F_{\dot{\varepsilon}}$ only caused by the true strain-rate effect is obtained, which is shown in Figure 27. Eq.(13) fits the simulation data well, where the determination coefficient is $0.91,0.89$ and 0.84 , respectively.

$$
\left\{\begin{array}{l}
\phi 50 \mathrm{~mm}: D I F_{\dot{\varepsilon}}=0.6917[\lg (\dot{\varepsilon})]^{3}-3.5289[\lg (\dot{\varepsilon})]^{2}+6.0289 \lg (\dot{\varepsilon})-2.2941 \\
\phi 74 \mathrm{~mm}: D I F_{\dot{\varepsilon}}=9.0898[\lg (\dot{\varepsilon})]^{3}-56.9029[\lg (\dot{\varepsilon})]^{2}+118.044 \lg (\dot{\varepsilon})-79.7806 \\
\phi 50,74 \mathrm{~mm}: D I F_{\dot{\varepsilon}}=1.7362[\lg (\dot{\varepsilon})]^{3}-9.5157[\lg (\dot{\varepsilon})]^{2}+17.2729 \lg (\dot{\varepsilon})-9.1879
\end{array}\right.
$$

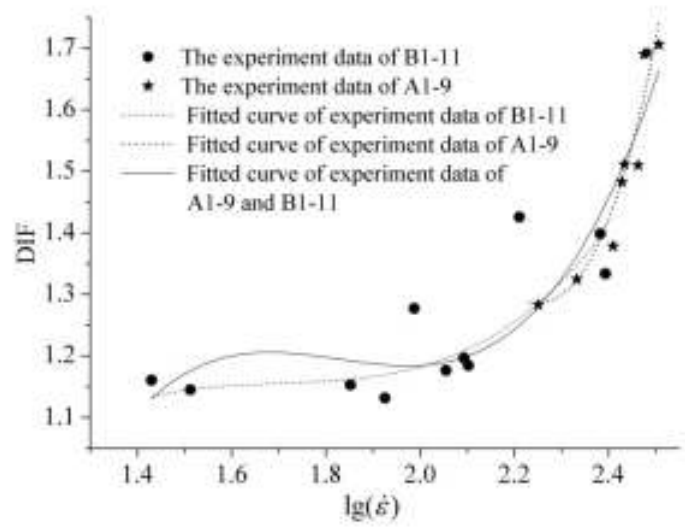

Figure 27: The $D I F_{\dot{\varepsilon}}$ versus $\lg (\dot{\varepsilon})$ curve of granite.

It is observed from Figure 27 that the true strain-rate effect obtained from SHPB experimental data of samples with different diameters agrees well, which indicates that the determined true strain-rate effect is independent of specimen diameter, thus the inertial effect is indeed eliminated. 
The results of true strain-rate effect are reliable. The contribution of DIF increment caused by the real strain-rate effect, lateral inertia effect and end friction effect to the $D I F_{\text {tot }}$ increment is shown in Figure 28, where the contribution is the ratio of DIF increment caused by the real strain-rate effect, lateral inertia effect and end friction effect, respectively, and the DIF $F_{t o t}$ increment. It is found from Figure 28 that the contribution of real strain-rate effect to DIF is the largest. When the strain-rate is greater than a certain value, the contribution of the lateral inertia effect and end friction effect to DIF cannot be ignored.

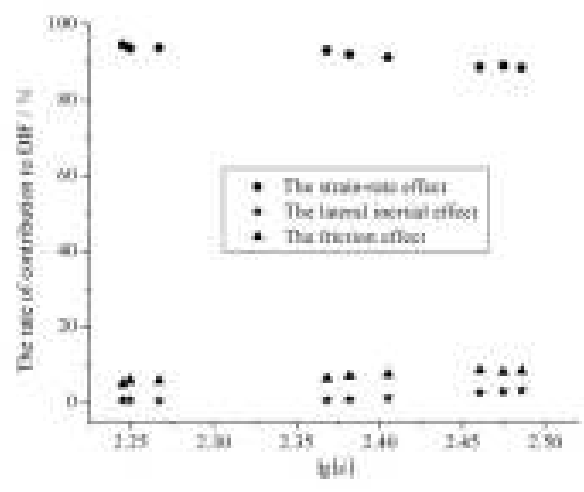

(a) $\phi 50 \mathrm{~mm}$

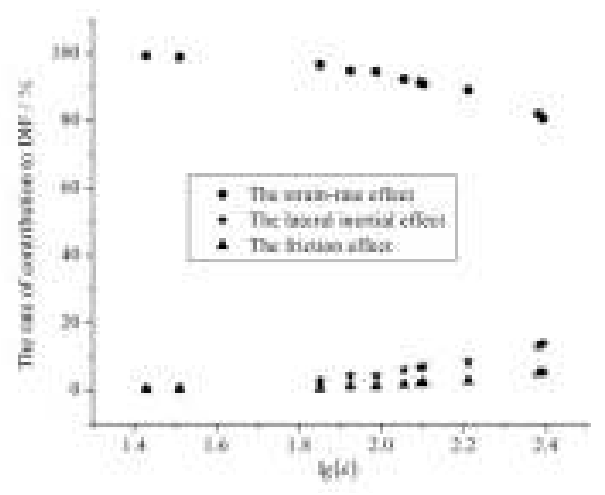

(b) $\phi 74 \mathrm{~mm}$

Figure 28: The contribution of real strain-rate effect, lateral inertial effect and end friction effect to DIF.

\section{CONCLUSIONS}

(1) Under the condition of triaxial compression, the compressive strength of granite is higher than that under uniaxial compression. The compressive strength increases with increasing confinement pressure, but with the increase of confinement pressure the range of strength increased tends to decrease. The axial failure strain increases with increasing the confinement pressure. The failure mode of granite samples closely relates to their composition and structure as well as the stress state. With increasing confinement pressure, the bondage of samples is more tightly, the elastic limit strain will be smaller, and thus the elastic modulus increases accordingly.

(2) Strain-rate not only affects the compressive strength of granite samples, but also the broken degree and failure pattern of granite samples.

(3) Based on numerical SHPB tests, the lateral inertia effect and end friction effect can be determined. Then eliminating the dynamic compressive strength increment caused by both the lateral inertial effect and end friction effect from the measured dynamic compressive strength of granite, the true strain-rate effect of granite in SHPB tests is determined. And the reliability of the obtained true strain-rate effect is verified. In addition, the numerical method can be used to determine the true strain-rate effect of other brittle materials.

(4) In SHPB tests on granite, the contribution of true strain-rate effect to DIF is biggest. At the same time, for samples of small diameter when strain-rates are beyond a critical strain-rate, and samples of large diameter in the studied range of strain-rate, the DIF increment caused by the lateral inertia effect and end friction effect also cannot be neglected. 


\section{Acknowledgements}

The authors would like to acknowledge the sponsor by the National Natural Science Foundation of China (51308480) and National Science and Technology Major Project of the Ministry of Science and Technology of China (2012ZX04077-021).

\section{References}

Bischoff, P.H., Perry, S.H., (1991). Compression behavior of concrete at high strain-rate. Materials and Structures 24(6): 425-450.

Brace, W.F., Jones, A.H., (1971). Comparison of uniaxial deformation in shock and static loading of three rocks. Journal of Geophysical Research 13(6): 4913-4921.

Dai, F., Huang, S., Xia, K.W., et al., (2010). Some fundamental issues in dynamic compression and tension tests of rocks using split Hopkinson pressure bar. Rock Mechanics and Rock Engineering 43(6): 657-666.

Dai, F., Xia, K.W., (2013). Laboratory measurements of the rate dependence of the fracture toughness anisotropy of Barre granite. International Journal of Rock Mechanics and Mining Science 60: 57-65.

Dai, F., Xia, K.W., Nasseri, M.H.B., (2013). Micromechanical model for the rate dependence of the fracture toughness anisotropy of Barre granite. International Journal of Rock Mechanics and Mining Science 63: 113-121.

Hao, H., Hao, Y., Li, Z.X., (2012). Numerical quantification of factors influencing high-speed impact tests of concrete material. Advances in Protective Structures Research: 97-130.

Hao, Y., Hao, H., Jiang, G.P., et al., (2013). Experimental confirmation of some factors influencing dynamic concrete compressive strengths in high-speed impact tests. Cement and Concrete Research 52(10): 63-70.

Hao, Y., Hao, H., Li, Z.X., (2013). Influence of end friction confinement on impact tests of concrete material at high strain rate. International Journal of Impact Engineering 60(10): 82-106.

Hibbitt, Karlson \& Sorensen., (2007). ABAQUS Theory Manual, version 6.7-1. USA.

Hong, L., Li, X.B., Ma, C.D., et al., (2008). Study on size effect of rock dynamic strength and strain rate sensitivity. Chinese Journal of Rock Mechanics and Engineering 27(3): 526-533.

Iwamoto, T., Yokoyama, T. (2012). Effects of radial inertia and end friction in specimen geometry in split Hopkinson pressure bar tests: A computational study. Mechanics of Materials 51: 97-109.

Li, Q.M., Lu, Y.B., Meng, H., (2009). Further investigation on the dynamic compressive strength enhancement of concrete-like materials based on split Hopkinson pressure bar tests, Part II: numerical simulations. International

Li, Q.M., Meng, H., (2003). About the dynamic strength enhancement of concrete-like materials in a split Hopkinson pressure bar test. International Journal of Solids and Structures 40(2): 343-360.

Journal of Impact Engineering 36(12): 1335-1345.

Liang, X.Y., Wang, Y.H., Wang, Z.D., (2008). Effect of lateral inertia and strain rate for RPCs under impact loading. Journal of Beijing Jiaotong University 32(4): 58-62. (in Chinese)

Lu, Y.B., Li, Q.M., (2011). A correction methodology to determine the strain-rate effect on the compressive strength of brittle material based on SHPB testing. International Journal of Protective Structures 2(1): 127-138.

Lu, Y.B., Li, Q.M., Ma, G.W., (2010). Numerical investigation on the dynamic compressive strength of rocks based on split Hopkinson pressure bar tests. International Journal of Rock Mechanics and Mining Science 47(5): 829-838.

Mu, Z.C., Dancygier, A.N., Zhang, W., et al., (2012). Revisiting the dynamic compressive of concrete-like materials. International Journal of Impact Engineering 49(5): 91-102.

Ren, X.T., Zhou, T.Q., Zhong, F.P., et al., (2010), Experimental study for the dynamic mechanical behavior of granite. Journal of Experimental Mechanics 25(6): 723-730. (in Chinese) 
Yu, S.S., Lu, Y.B., Cai, Y., (2013). A new numerical method to determine real strain-rate effect for rock-like materials. Chinese Journal of Rock Mechanics and Engineering 32(supp.2): 3283-3290. (in Chinese)

Zhai, Y., Ma, G.W., Zhao, J.H., et al., (2007). Dynamic failure analysis on granite under impact compressive load. Chinese Journal of Geotechnical Engineering 29(3): 385-390. (in Chinese)

Zhang, Q.B., Zhao, J., (2013). A Review of dynamic experimental techniques and mechanical behaviour of rock materials. Rock Mechanics and Rock Engineering. doi: 10.1007/s00603-013-0463-y

Zhou, X.Q., Hao, H., (2008). Modeling of compressive behaviour of concrete-like materials at high strain rate. International Journal of Solids and Structures 45(17): 4648-4661.

Zhu, W.C., Bai, Y., Li, X.B., et al., (2012). Numerical simulation on rock failure under combined static and dynamic loading during SHPB tests. International Journal of Impact Engineering 49(11): 142-157. 